\section{Accepted Manuscript}

This article can be cited before page numbers have been issued, to do this please use: R. H. Verschueren, P. Gilles, S. Van Mileghem and W. M. De Borggraeve, Org. Biomol. Chem., 2021, DOI:

\section{Organic \& Biomolecular Chemistry}

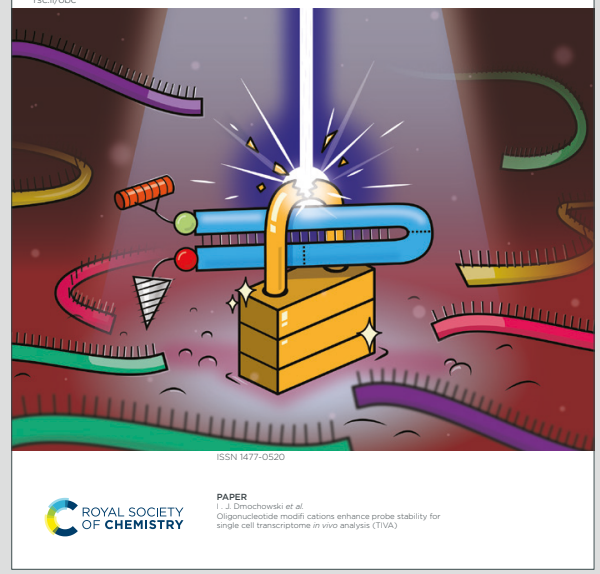

This is an Accepted Manuscript, which has been through the Royal Society of Chemistry peer review process and has been accepted for publication.

Accepted Manuscripts are published online shortly after acceptance, before technical editing, formatting and proof reading. Using this free service, authors can make their results available to the community, in citable form, before we publish the edited article. We will replace this Accepted Manuscript with the edited and formatted Advance Article as soon as it is available.

You can find more information about Accepted Manuscripts in the Information for Authors.

Please note that technical editing may introduce minor changes to the text and/or graphics, which may alter content. The journal's standard Terms \& Conditions and the Ethical guidelines still apply. In no event shall the Royal Society of Chemistry be held responsible for any errors or omissions in this Accepted Manuscript or any consequences arising from the use of any information it contains. 


\title{
Solvent-Free $N$-Boc Deprotection by Ex Situ Generation of Hydrogen Chloride Gas
}

Received 00th January 20xx, Accepted 00th January 20xx

DOI: $10.1039 / \times 0 \times x 00000 x$

\author{
Rik H. Verschueren, Philippe Gilles, Seger Van Mileghem and Wim M. De Borggraeve *
}

\begin{abstract}
An efficient, scalable and sustainable method for the quantitative deprotection of the tert-butyl carbamate ( $N$-Boc) protecting group is described, using down to near-stoichiometric amounts of hydrogen chloride gas in solvent-free conditions. We demonstrate the ex situ generation of hydrogen chloride gas from sodium chloride and sulfuric acid in a twochamber reactor, introducing a straightforward method for controlled and stoichiometric release of $\mathrm{HCl}$ gas. The solventfree conditions allow deprotection of a wide variety of $N$-Boc derivatives to obtain the hydrochloride salts in quantitative yields. The procedure obviates the need for any work-up or purification steps providing an uncomplicated green alternative to standard methods. Due to the solvent-free, anhydrous conditions, this method shows high tolerance towards acid sensitive functional groups and furnishes expanded functional group orthogonality.
\end{abstract}

\section{Introduction}

Protecting groups are principal elements in organic synthesis considering that complex intermediates and products typically contain a wide variety of functional groups. ${ }^{1,2}$ To prevent the formation of undesired bonds and side reactions, synthetic chemists make strategic use of their ability to mask and, at a later stage in the synthesis, liberate functional groups to unlock their desired reactivity. ${ }^{3}$ The tert-butyloxycarbonyl protecting group (Boc group) is one of the most important amino protecting groups and has contributed substantially to the achievements in present organic synthesis. ${ }^{4}$ Its applicability comes from the ability to be introduced into the molecule under mild conditions in a selective and high-yielding manner. The same requirements are to be expected for the cleavage, while keeping other protecting groups and unprotected functionalities unaffected by the deprotection conditions. This concept of orthogonally stable protecting groups is key in the synthesis of complex molecules. ${ }^{5}$ Due to its acid lability, the most commonly used Boc-deprotection procedures use solutions of $25-50 \%$ trifluoroacetic acid in DCM or $\mathrm{HCl}$ solutions. ${ }^{2}$ Consequently, other acid labile protecting groups are typically not tolerated in these procedures, imposing restrictions on orthogonal strategies. In recent years, progress has been made using alternatives such as solid supported catalysis,, 6 high-temperature 7 ater 8 -11 and ionic liquid mediated deprotections. ${ }^{12,13}$ However, the $N$-Boc-deprotection toolbox still suffers from chemoselectivity limitations. Furthermore, practically all deprotection strategies require

KU Leuven, Department of Chemistry, Molecular Design and Synthesis, Celestijnenlaan 200F - box 2404, B-3001 Leuven, Belgium

tElectronic Supplementary Information (ESI) available: [details of any supplementary information available should be included here]. See DOI: $10.1039 / x 0 x \times 00000 x$ several post-cleavage manipulations such as quenching, removal of solvents and purification steps. It is estimated that in typical fine chemical and pharmaceutical batch syntheses, solvents account for 80 to $90 \%$ of mass utilization. ${ }^{14}$ Efforts have been made to improve on sustainability, but in reality, even the solvent-recycling and solvent-free $\mathrm{N}$-Boc deprotections still require post-synthesis manipulations and purification steps, inviting further improvement. ${ }^{12,15,16}$

To solve these current problems, we confided in our previous experience with gas chemistry. Herein, we present an $\mathrm{N}$-Boc deprotection method with high functional group tolerance and expanded orthogonality while also being a green alternative to standard methods. Despite the fact that gases are commonly avoided and undervalued in a laboratory setting for practical and safety reasons, they can be convenient reagents with great potential for high atom economy. ${ }^{17-20}$ Moreover, gas-solid reactions have achieved unsurpassed atom economy due to their solvent-free nature and elimination of any purifying workup upon full conversion. ${ }^{21,22}$ A literature survey reveals that hydrogen chloride gas has the potential to cleave tert-butyl carbamates. ${ }^{23-25}$ However, it has never been extensively studied, and no general protocol has been described. The few mentions that do exist typically use a pressurized gas cylinder to pass $\mathrm{HCl}$ gas through the solid substrate for several hours or even overnight. Though effective, lecture bottles are associated with high cost and risk of leakage or even explosion. Moreover, excessive amounts of a constant stream of the harmful, corrosive gas in open air are required to drive the reaction to decent conversion. This set-up and the lack of precautionary measures to safely evacuate the excess gas make it impractical and exposes the operator to severe risks. Furthermore, the continuous supply of gas needed, adds up to excessive quantities hampering the potential towards a sustainable methodology. In recent years, ex situ gas generation has proven to be an enabling technology with an improved safety profile 
allowing precise control over stoichiometry. ${ }^{19,} 20$ Using a twochamber reactor, we envisioned the liberation of $\mathrm{HCl}$ gas from cheap and readily available precursor molecules $(\mathrm{NaCl}$ and $\left.\mathrm{H}_{2} \mathrm{SO}_{4}\right)^{26}$ in one chamber, which subsequently diffuses to the adjacent chamber where it participates in the deprotection reaction (Scheme 1). The byproducts of the reaction, $\mathrm{CO}_{2}$ and isobutene, are both gaseous. As a consequence, upon quantitative conversion it eliminates the need for any work-up or purification steps. Thereby, a truly solvent-free procedure is achieved where the whole process from substrate to pure product does not consume any solvent. These types of gas-solid and gas-liquid reactions are able to achieve remarkable waste minimization. 27,28 Finally, the anhydrous nature of this procedure has shown the potential to eliminate unwanted hydrolysis of other acid sensitive functional groups, thus increasing functional group tolerance and orthogonality.

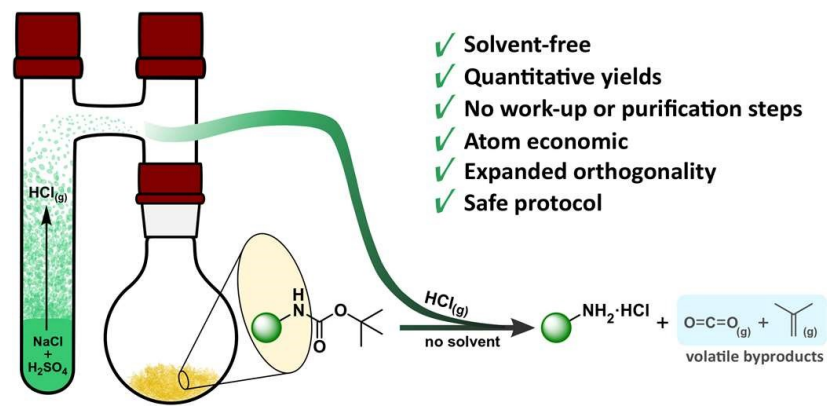

Scheme 1 Solvent-free deprotection of $\mathrm{N}$-Boc compounds by ex situ generation of $\mathrm{HCl}$ gas using a two-chamber reactor with a detachable product chamber.

\section{Results and discussion}

\section{Optimization}

The solvent-free $\mathrm{N}$-Boc deprotection strategy was first evaluated by generating an excess of $\mathrm{HCl}$ gas ( 5 equiv. $\mathrm{NaCl}$ and 5 equiv. $\mathrm{H}_{2} \mathrm{SO}_{4}$ ) in Chamber $\mathrm{A}$ of a two-chamber reactor, which then diffuses to Chamber $\mathrm{B}$ to deprotect $\mathrm{N}$-Boc benzylamine. To our surprise, after reacting for 1 hour under solvent-free conditions $38 \%$ of the substrate had been deprotected and converted towards the hydrochloride salt (Table 1, entry 2). We realize that in the domain of gas-solid chemistry, the kinetic challenges are often of physical rather than chemical nature. Therefore, we hypothesize that the macroscopic size of the substrate crystals prevents the $\mathrm{HCl}$ gas from interacting with the substrate molecules in the core of the crystals. To solve this, we grinded our substrate with pestle and mortar to increase the surface to volume ratio. Under otherwise identical conditions, the conversion towards the hydrochloride salt increased to $63 \%$ using the powdered substrate (entry 3 ). Further screening of reaction conditions was carried out to minimize reagent use while maintaining fast reaction completion. The optimization table summarizes the results (Table 1 ). By using a 1:1 ratio of $\mathrm{NaCl} / \mathrm{H}_{2} \mathrm{SO}_{4}$, apart from gas generation in Chamber $\mathrm{A}$, a sticky paste also developed in that same chamber. We rationalize that as a result of inefficient mixing, not all $\mathrm{NaCl}$ is converted into $\mathrm{HCl}$ gas. This was addressed by using an excess of $\mathrm{H}_{2} \mathrm{SO}_{4}(0.5 \mathrm{~mL})$ as it dissolves $\mathrm{NaCl}$ well and thereby ensures better conversion towards $\mathrm{HCl}$ gas. Using only 3 equivalents of $\mathrm{NaCl}$ and $0.5 \mathrm{~mL}$ of sulfuric acid, we are able to achieve quantitative NMR conversion after only 1 hour (entry 4). Remarkably, it was established that the reaction can be driven to completion by generating near-stoichiometric amounts of $\mathrm{HCl}$ gas (entries 78). However, it was decided to proceed by generating 3 equivalents of $\mathrm{HCl}$ gas to ensure full conversion in short reaction times ( $<1$ hour). Undoubtedly, it is an advantage to carry out this transformation under solvent-free conditions. Nonetheless, for comparison, we carried out the same reaction procedure with the exception of dissolving the substrate in different solvents (DCM, EtOH and dioxane). None of these systems performed better than the solvent-free procedure, displaying an apparent kinetic advantage (entries 9-11).

After achieving full conversion at fast reaction times and low stoichiometry, we considered the possibility to isolate our products quantitatively. To minimize the handlings, we devised a new type of two-chamber reactor with a detachable chamber designed as a round-bottom flask (see Scheme 1 and SI). Due to the solvent-free procedure and gaseous nature of the byproducts $\left(\mathrm{CO}_{2}\right.$ and isobutene), chamber $\mathrm{B}$ can simply be detached after reaction completion to isolate the corresponding product in quantitative yield without any further handling. ${ }^{29}$ Besides decreasing the overall labor intensity of this deprotection method, this allows consecutive product manipulation without transferring the compound. With the increased interest in ex situ gas generation, we believe this new reactor design will also prove useful in other chemical transformations using gaseous reagents.

Table 1 Optimization of $N$-Boc deprotection of $N$-Boc benzylamine by ex situ generation of $\mathrm{HCl}$ gas.

\begin{tabular}{|c|c|c|c|c|c|}
\hline \multirow{2}{*}{\multicolumn{4}{|c|}{$\begin{array}{l}\text { Chamber A } \\
\mathrm{NaCl}(\mathrm{X} \text { equiv.) } \\
\mathrm{H}_{2} \mathrm{SO}_{4} \text { (Y equiv.) } \\
\text { Chamber } \mathrm{B} \\
\text { substrate (1 equiv.) } \\
\text { solvent, } \mathrm{rt}\end{array}$}} & & \multirow{2}{*}{$\mathrm{NH}_{2} \cdot \mathrm{HC}$} \\
\hline & & & & & \\
\hline Entry & $\begin{array}{c}\mathrm{NaCl} \\
\text { (equiv.) }\end{array}$ & $\begin{array}{c}\mathrm{H}_{2} \mathrm{SO}_{4} \\
\text { (equiv.) }\end{array}$ & Solvent & Time & Yield \\
\hline 1 & 0 & 5 & - & $1 \mathrm{~h}$ & $0 \%$ \\
\hline $2^{c}$ & 5 & 5 & - & $1 \mathrm{~h}$ & $38 \%$ \\
\hline 3 & 5 & 5 & - & $1 \mathrm{~h}$ & $63 \%$ \\
\hline 4 & 3 & $0.5 \mathrm{~mL}$ & - & $1 \mathrm{~h}$ & $>99 \%$ \\
\hline $5^{c}$ & 3 & $0.5 \mathrm{~mL}$ & - & $1 \mathrm{~h}$ & $70 \%$ \\
\hline 6 & 3 & 3 & - & $1 \mathrm{~h}$ & $20 \%$ \\
\hline 7 & 1.3 & $0.5 \mathrm{~mL}$ & - & $20 \mathrm{~h}$ & >99\% \\
\hline 8 & 1.2 & $0.5 \mathrm{~mL}$ & - & $20 \mathrm{~h}$ & $85 \%$ \\
\hline $9^{d}$ & 3 & $0.5 \mathrm{~mL}$ & DCM & $1 \mathrm{~h}$ & $7 \%$ \\
\hline $10^{d}$ & 3 & $0.5 \mathrm{~mL}$ & ethanol & $1 \mathrm{~h}$ & $16 \%$ \\
\hline $11^{d}$ & 3 & $0.5 \mathrm{~mL}$ & dioxane & $1 \mathrm{~h}$ & $26 \%$ \\
\hline
\end{tabular}

a Reaction conditions: Chamber A: $\mathrm{NaCl}, \mathrm{H}_{2} \mathrm{SO}_{4}$ at rt. Chamber B: $\mathrm{N}$-Boc benzylamine $(0.5 \mathrm{mmol})$ at $\mathrm{rt}$; ${ }^{\mathrm{b}}$ Determined by ${ }^{1} \mathrm{H} \mathrm{NMR}$; ${ }^{\mathrm{C}}$ Unground, crystalline substrate; ${ }^{\mathrm{d}} 0.5 \mathrm{~mL}$ of solvent in Chamber $\mathrm{B}$. 


\section{PAPER}

$$
\mathrm{O}_{\mathrm{O}}^{\mathrm{N}} \prod_{\text {no solvent }}^{\mathrm{HCl}} \longrightarrow \mathrm{H}^{\mathrm{NH}_{2} \cdot \mathrm{HCl}}
$$

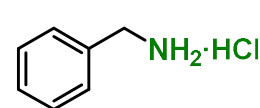

$1,>99 \%$

$\mathrm{t}=1 \mathrm{~h}$

$\langle\underset{\mathrm{H}}{\mathrm{N}} \mathrm{N} \cdot \mathrm{HCl}$

$8,>99 \%$

$\mathrm{t}=1 \mathrm{~h}$<smiles>N[C@@H](Cc1c[nH]c2ccccc12)C(=O)OCc1ccccc1</smiles>

$14^{\mathrm{b}},>99 \%$

$\mathrm{t}=14 \mathrm{~h}$

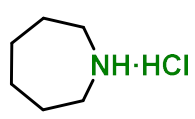

3, $>99 \%$

$\mathrm{t}=1 \mathrm{~h}$

$\overbrace{\mathrm{NH}_{2} \cdot \mathrm{HCl}}^{\mathrm{OHH}}$

$10,>99 \%$

$\mathrm{t}=1 \mathrm{~h}$<smiles>C[C@H](OCc1ccccc1)[C@H](N)C(=O)O</smiles>

$15,>99 \%$

$\mathrm{t}=5 \mathrm{~h}$
$\mathrm{NH}_{2} \cdot \mathrm{HCl}$

4, $>99 \%$

$\mathrm{t}=1 \mathrm{~h}$<smiles>CC(C)C[C@H](N)C(=O)O</smiles>

$11,>99 \%$

$\mathrm{t}=3 \mathrm{~h}$
$=\mathrm{NH}_{2} \cdot \mathrm{HCl}$

5, $>99 \%$

$\mathrm{t}=1 \mathrm{~h}$
$\mathrm{NH}_{2}^{\mathrm{NH}_{2} \cdot \mathrm{HCl}}$

$6,>99 \%$

$\mathrm{t}=1 \mathrm{~h}$
$\overbrace{0}^{\mathrm{NH}_{2} \cdot \mathrm{HCl}}$

$7,>99 \%$

$\mathrm{t}=3 \mathrm{~h}$<smiles>CSCC[C@H](N)C(=O)O</smiles><smiles>COC(=O)[C@H](N)Cc1ccc(O)cc1</smiles>

$12,>99 \%$ $\mathrm{t}=1 \mathrm{~h}$

$13,>99 \%$ $\mathrm{t}=14 \mathrm{~h}$<smiles>[R]OC(=O)C[C@H](N)C(=O)O</smiles><smiles>[R]OC[C@H](N)C(=O)O</smiles><smiles>COC(=O)[C@@H]1CCC(=O)N1</smiles>

$16^{\prime}(\mathrm{R}=t \mathrm{Bu}), \mathrm{t}=16 \mathrm{~h}$

$16(\mathrm{R}=\mathrm{H}),>99 \%$

$18,>99 \%$

$\mathrm{t}=2 \mathrm{~h}$<smiles>Cc1ccc(S(N)(=O)=O)cc1</smiles><smiles>CC1(C)OB(c2cn[nH]c2)OC1(C)C</smiles><smiles>CC1(C)OB(c2ccc(N)cc2)OC1(C)C</smiles>

$19,>99 \%$

$\mathrm{t}=5 \mathrm{~h}$

$t=4 \mathrm{~h}$

$\mathrm{t}=4 \mathrm{~h}$

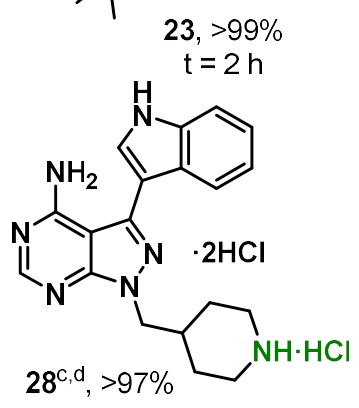

$24,>99 \%$

$\mathrm{t}=14 \mathrm{~h}$

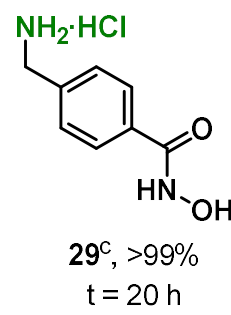

Scheme 2 Solvent-free deprotection of $\mathrm{N}$-Boc protected amino groups by ex situ generation of $\mathrm{HCl}$ gas using a two-chamber reactor with detachable chamber. a Reaction conditions: at room temperature under argon atmosphere; Chamber A: $\mathrm{NaCl}$ ( $1.5 \mathrm{mmol}, 3$ equiv.); Chamber $\mathrm{B}$ : substrate $\left(0.5 \mathrm{mmol}, 1.0\right.$ equiv.); Finally, $0.5 \mathrm{~mL} \mathrm{H}_{2} \mathrm{SO}_{4}$ was added by injection through the septum in chamber A. See $\mathrm{SI}$ and Instructional Video. ${ }^{\mathrm{b}} \mathrm{NaCl}\left(2.5 \mathrm{mmol}, 5.0\right.$ equiv.). ${ }^{\mathrm{c}} \mathrm{NaCl}\left(5 \mathrm{mmol}, 10.0\right.$ equiv.). ${ }^{\mathrm{d}} 10 \mathrm{mg}$ scale.

\section{Substrate scope}

Next, we applied this efficient and green deprotection procedure to more complex amines and other nitrogenprotected substrates. The generality of this procedure is shown in Scheme 2, demonstrating efficient deprotection of various classes of nitrogen-containing functional groups (primary and secondary amines, anilines, (sulfon)amides, carboximidamides, amino acids and heteroaryls). Depending on the ease of deprotection of the substrate, more equivalents of $\mathrm{HCl}$ gas were generated. All substrates display quantitative isolated yields after reaction times varying from 1 hour to 20 hours. We started with several simple primary, secondary and benzylic protected amines, which could be fully deprotected within 1 hour (1-5). Noteworthy are the liquid substrates that were converted to the solid hydrochloride products in quantitative yields under 
solvent-free conditions $(\mathbf{2}, \mathbf{3}, \mathbf{2 6})$. Some other solid substrates went through a viscous liquid state during the transformation to also end up as the solid hydrochloride product. However, most substrates in this study remain in the solid state during the whole deprotection procedure. Interestingly, unactivated alkenes and alkynes are unaffected in this method $(\mathbf{4}, \mathbf{5})$. Aminoaryls were readily deprotected in short reaction times to yield 6 and 7. $\mathbf{N}$-Boc protected heteroaryls such as imidazoles and pyrazoles were no exception $(\mathbf{8}, \mathbf{2 3})$. Furthermore, $N$-Boc$1 \mathrm{H}$-pyrazole-1-carboxamidine was isolated in quantitative yield as $\mathbf{9}$. Considering the great value of amino acids to medicinal chemists, we investigated the deprotection of several amino acid derivatives. Simple amino acids could be deprotected after reaction times varying from 1 to 3 hours $(10,11,12) . N$-Boc- $L$ tryptophan benzyl ester required 5 equivalents of $\mathrm{HCl}$ to fully deprotect and $\mathbf{1 4}$ was quantitatively isolated after 14 hours of reaction time. The reaction displayed perfect chemoselectivity as the benzylic ester protecting group was unaffected. Similarly, the benzyl ether protecting group of $\mathrm{N}$-Boc-O-benzyl-Lthreonine also remained intact to yield 15. Gratifyingly, unlike many alternative methods, no tert-butylation of the tyrosine phenol and tryptophan indole were observed $(\mathbf{1 3}, \mathbf{1 4})$. This problem occurs when tert-butyl cations are formed during Bocdeprotection and unwantedly react with a nucleophile. ${ }^{30-32}$ Due to the solvent-free nature of this procedure, there is no possibility for a solvated tert-butyl cation to exist and cause complications. This also obviates the need of adding scavengers. ${ }^{33-35}$ Tert-butyl ester $\mathbf{1 6}$ and tert-butyl ether $\mathbf{1 7}$ are also deprotected using this method. The simultaneous deprotection of the $\mathrm{N}$-Boc group and tert-butyl ester/ether was possible using only 3 equivalents of $\mathrm{HCl}$ gas. Moreover, these examples further emphasize the labor-, waste- and costeffectiveness of this procedure. To verify the enantiomeric purity of the amino acid products, they were submitted to chiral HPLC and compared to commercially available racemic mixtures. Single peaks were observed at the corresponding retention times whereas the racemic mixtures gave two. The specific optical rotations also confirmed no detectable racemization. Boc-L-pyroglutamic acid methyl ester was isolated quantitatively as free base $\mathbf{1 8}$ rather than the hydrochloride salt. This led us to conclude that nitrogenprotected substrates with low basicity do not consume the $\mathrm{HCl}$ gas after deprotection. The deprotection of $\mathrm{N}$-Boc tosylamide towards free base 19 further supported this hypothesis. Consequently, these particular substrate classes have the potential to be catalytically deprotected. This was confirmed by deprotection of Boc-L-pyroglutamic acid methyl ester and $\mathrm{N}$ Boc tosylamide using only 0.5 equivalents of $\mathrm{HCl}$ gas. Over the period of two days, both substrates were deprotected in $>94 \%$ yield (Scheme 3a). In contrast, substrates containing additional basic functional groups are converted to dihydrochloride salts as demonstrated in compound $\mathbf{2 0}$.

Substrates bearing acid-labile functional groups were subjected to our method to investigate the functional group compatibility. To our delight, methyl and benzyl esters and ethers remained stable under these conditions $(\mathbf{1 3}, \mathbf{1 4}, \mathbf{1 5}, \mathbf{1 8})$. Furthermore, due to the anhydrous and neat conditions, the presence of an acetal group is well tolerated and $\mathbf{2 1}$ was quantitatively obtained with perfect chemoselectivity. Similarly, boronate esters are also known to undergo decomposition using other $N$-Boc deprotection methods while under our conditions aliphatic, aryl as well as heteroaryl pinacol boronate esters 22, 23, 24 behaved well. ${ }^{11}, 36,37$ The mild nature of this procedure is further highlighted by the chemoselective deprotection in the presence of acid sensitive silyl ethers (25). The same was true in the presence of an enol triflate (26). Within our lab, this procedure has already proven extremely useful. During the synthesis of a pyrazolo[3,4- $d$ ]pyrimidine-based protein kinase D inhibitor (28), $\mathrm{N}$-Boc was initially selected as the protecting group in order to install a piperidine moiety. At the time, multiple efforts to cleave the $N$-Boc-group under acidic conditions failed to yield pure 28 due to side reactions. ${ }^{38}$ Upon developing this procedure, we discovered that the solvent-free conditions eliminated these side reactions. Hereby, we enabled the $N$-Boc deprotection of these scaffolds $(\mathbf{2 7}, \mathbf{2 8})$ in quantitative yields without requiring any purifying work-up. Given the importance of hydroxamic acids as strong metal ion chelators, ${ }^{39}$ we investigated the chemoselectivity of the $N$-Boc deprotection of a benzohydroxamic acid. Attempting several standard deprotection methods for 4-(boc-aminomethyl)- $N$ hydroxybenzamide always led to an arduous task due to side product formation. Employing the procedure described in this work, we were able to deprotect this substrate without affecting the hydroxamic acid moiety to obtain 29 in quantitative yield.

\section{a) Catalytic N-Boc deprotection}<smiles>COC(=O)[C@@H]1CCC(=O)N1C(=O)OC(C)(C)C</smiles>

b) Scalability.

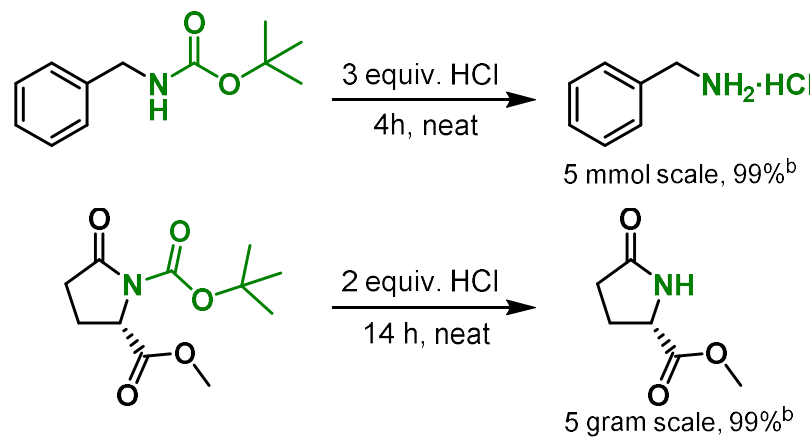

Scheme 3 a) Conceptual examples of the catalytic $N$-Boc deprotection. a) Scale-up of the solvent-free $\mathrm{N}$-Boc deprotection. ${ }^{\text {a NMR yields. }}{ }^{\mathrm{b}}$ Isolated yields. 
All substrates containing acid labile functionalities are deprotected under dry conditions (flame-dried glassware, argon atmosphere, sulfuric acid acting as a desiccant $\left.{ }^{40}\right)$. If not, minor side products were observed for some substrates (e.g. in the presence of water, acid catalysed hydrolysis can occur.). Therefore, when handled under the proposed dry and solventfree conditions, the presence of these protecting groups and functionalities becomes inconsequential. However, we did observe that epoxides, activated olefins and the $\mathrm{N}-\mathrm{Cbz}$ group were not stable under these conditions and reacted with $\mathrm{HCl}$.

Finally, this procedure is easily scalable by simply using a larger two-chamber reactor. This was illustrated by deprotection of $\mathrm{N}$ Boc benzylamine on a $5 \mathrm{mmol}$ scale and Boc-L-pyroglutamic acid methyl ester on a 5 gram scale resulting in quantitative isolated yields of 1 and 18 (Scheme 3b). ${ }^{41}$ This procedure was shown to be scalable on a laboratory scale and can be used as an enabling framework towards kilogram scale gas-solid $N$-Boc deprotections. ${ }^{27}$

\section{Conclusions}

In summary, a procedure has been developed for the clean removal of $\mathrm{N}$-Boc protecting groups and isolation of products in quantitative yields without the need for purification or work-up. The reaction proceeds under solvent-free conditions at room temperature, using down to near-stoichiometric amounts of ex situ generated $\mathrm{HCl}$ gas. We devised an operationally simple twochamber reactor with a detachable chamber allowing transferfree product isolation and follow-up reactions. Besides being a labor-, waste- and cost-effective $N$-Boc deprotection method, it displays a broad scope with respect to the $N$-Boc groups that can be deprotected and functional groups that are tolerated. The high tolerance towards otherwise acid sensitive functional groups and expanded functional group orthogonality will likely render it a useful tool in protecting group strategies for complex organic syntheses. Moreover, this solvent-free procedure and new reactor design are promising for further sustainable synthetic purposes.

\section{Conflicts of interest}

There are no conflicts of interest to declare.

\section{Acknowledgements}

We are grateful to Bart Van Huffel (KU Leuven) for the assistance with NMR measurements and performing the elemental analyses and Wouter Stuyck (cMACS - KU Leuven) for performing the chiral HPLC analyses. R.H.V. and P.G. thank the Research Foundation - Flanders (FWO) for support received through fellowships 11D6220N and 1S09017N. R.H.V. would like to thank Elien J. Van der Gucht for the unconditional support.

\section{Notes and references}

1. M. Schelhaas and H. Waldmann, Angew. Chem. Int. Ed., 1996, 35, 2056-2083.
A. Isidro-Llobet, M. Álvarez and F. Albericio, Chem. Rev., 2009, 109, 2455-2504.

P. G. M. Wuts and T. W. Greene, in Greene's Protective Groups in Organic Synthesis, 2006, DOI: 10.1002/9780470053485.ch1, pp. 1-15.

S. D. Roughley and A. M. Jordan, J. Med. Chem., 2011, 54, 3451-3479.

P. J. Kocieński, Protecting Groups, Georg Thieme Verlag, Stuttgart, New York, 3rd Edition edn., 2005.

E. Langille, C. S. Bottaro and A. Drouin, J. Flow Chem., 2020, 10, 377-387.

J. Wu, C. Zheng, B. Li, J. M. Hawkins and S. L. Scott, React. Chem. Eng., 2021, DOI: 10.1039/DORE00398K.

G. Wang, C. Li, J. Li and X. Jia, Tetrahedron Lett., 2009, 50, 1438-1440.

J. Wang, Y.-L. Liang and J. Qu, Chem. Commun., 2009, DOI:

10.1039/B910239F, 5144-5146.

A. R. Bogdan, M. Charaschanya, A. W. Dombrowski, Y. Wang and S. W. Djuric, Org. Lett., 2016, 18, 1732-1735.

B. Li, R. Li, P. Dorff, J. C. McWilliams, R. M. Guinn, S. M. Guinness, L. Han, K. Wang and S. Yu, J. Org. Chem., 2019, 84, 4846-4855.

S. S. Bhawal, R. A. Patil and D. W. Armstrong, RSC Adv., 2015, 5, 95854-95856.

S. Majumdar, J. De, A. Chakraborty, D. Roy and D. K. Maiti, RSC Adv., 2015, 5, 3200-3205.

D. J. C. Constable, C. Jimenez-Gonzalez and R. K. Henderson, Org. Proc. Res. Dev., 2007, 11, 133-137.

Chemistry, 2017, 7, 140-144.

G. Pavan Kumar, D. Rambabu, M. V. Basaveswara Rao and M. Pal, Journal of Chemistry, 2013, 2013, 5.

D. Shonnard, A. Lindner, N. Nguyen, P. A. Ramachandran, D. Fichana, R. Hesketh, C. S. Slater and R. Engler, in Kent and Riegel's Handbook of Industrial Chemistry and Biotechnology, ed. J. A. Kent, Springer US, Boston, MA, 2007, DOI: 10.1007/978-0-387-27843-8_6, pp. 210-270.

C. J. Mallia and I. R. Baxendale, Org. Proc. Res. Dev., 2016, 20, 327-360.

S. D. Friis, A. T. Lindhardt and T. Skrydstrup, Acc. Chem. Res., 2016, 49, 594-605.

J. Demaerel, C. Veryser and W. M. De Borggraeve, React. Chem. Eng., 2020, 5, 615-631.

G. Kaupp and A. Kuse, Molecular Crystals and Liquid Crystals Science and Technology. Section A. Molecular Crystals and Liquid Crystals, 1998, 313, 361-366.

G. Kaupp, in Organic Solid State Reactions, ed. F. Toda, Springer Berlin Heidelberg, Berlin, Heidelberg, 2005, DOI: $10.1007 /$ b100997, ch. Organic Solid-State Reactions with $100 \%$ Yield, pp. 95-183.

V. Declerck, P. Nun, J. Martinez and F. Lamaty, Angew. Chem. Int. Ed., 2009, 48, 9318-9321.

O. Maurin, P. Verdié, G. Subra, F. Lamaty, J. Martinez and T.-X. Métro, Beilstein J. Org. Chem., 2017, 13, 2087-2093.

Y. Yeboue, B. Gallard, N. Le Moigne, M. Jean, F. Lamaty, J. Martinez and T.-X. Métro, ACS Sustain. Chem. Eng., 2018, 6, 16001-16004.

R. N. Maxson, H. S. Booth and S. J. Rehmar, in Inorganic Syntheses, 1939, DOI: 10.1002/9780470132326.ch52, pp. 147-149.

G. Kaupp, CrystEngComm, 2006, 8, 794-804. 

Technology, 2012, DOI: 10.1002/0471238961.solvkaup.a01, pp. 1-43.

29. In most cases it is impossible to achieve fully quantitative yields in organic synthesis. The reason being that after reaction completion with every handling (e.g. extraction, chromatography, crystalization, product transfer, ...) some product will be lost. However, if you eliminate all handlings and achieve full conversion this becomes feasible.

30. P. Sieber and B. Iselin, Helv. Chim. Acta, 1968, 51, 614-622.

31. Y. B. Alakhov, A. A. Kiryushkin, V. M. Lipkin and G. W. A. Milne, J. Chem. Soc. D Chem. Commun., 1970, DOI: 10.1039/C2970000406B, 406b-407.

32. Y. Yang, in Side Reactions in Peptide Synthesis, ed. Y. Yang, Academic Press, Oxford, 2016, DOI: 10.1016/B978-0-12801009-9.00003-3, pp. 43-75.

33. B. F. Lundt, N. L. Johansen, A. Vølund and J. Markussen, International Journal of Peptide and Protein Research, 1978, 12, 258-268.

34. D. A. Pearson, M. Blanchette, M. L. Baker and C. A. Guindon, Tetrahedron Lett., 1989, 30, 2739-2742.

35. A. Mehta, R. Jaouhari, T. J. Benson and K. T. Douglas, Tetrahedron Lett., 1992, 33, 5441-5444.

36. S. Collet, P. Bauchat, R. Danion-Bougot and D. Danion, Tetrahedron Asymm., 1998, 9, 2121-2131.

37. F. Bartoccini, S. Bartolucci, S. Lucarini and G. Piersanti, Eur. J. Org. Chem., 2015, 2015, 3352-3360.

38. P. Gilles, R. S. Kashyap, M. J. Freitas, S. Ceusters, K. Van Asch, A. Janssens, S. De Jonghe, L. Persoons, M. Cobbaut, D. Daelemans, J. Van Lint, A. R. D. Voet and W. M. De Borggraeve, Eur. J. Med. Chem., 2020, 205, 112638.

39. R. Codd, Coord. Chem. Rev., 2008, 252, 1387-1408.

40. D. M. Considine, in Van Nostrand's Scientific Encyclopedia, ed. D. M. Considine, 2007, DOI: 10.1002/0471743984.vse8990, ch. Desiccants.

41. It should be noted that we are under the impression that larger molecules and larger scale deprotections require longer reaction times or increased $\mathrm{HCl}$ stoichiometry. This could be a consequence of the gas-solid interactions required to drive the reaction, where the kinetics are subject to the physical availability of the carbamates. 